DOI 10.37882/2223-2982.2021.07.39

\title{
ЗАГОЛОВОК КАК КОМПОНЕНТ ЭЛЕКТРОННОГО НАУЧНО-ПОПУЛЯРНОГО ТЕКСТА
}

\section{HEADING AS A COMPONENT OF AN ELECTRONIC POPULAR SCIENCE TEXT \\ N. Khristoforova}

Summary: The study of the headings of an electronic popular science text is a relevant topic, since the headings are an important component, the "face" of the text: they carry a large information load, representing a brief description of the text content (brief content and semantic information). In addition, the heading is a means of influencing a reader, because if the reader pays attention to the heading and is interested in the text, he follows the link directly to the publication. The article explains the role of the heading in the process of understanding the electronic popular science text, analyzes the verbal and non-verbal means of its creation. The contradictory nature of the heading is also taken into account: it can act as an independent speech unit and as an equal element of the text. The article presents the results of the analysis of popular science texts headings from the electronic versions of the German-language periodicals "Bild der Wissenschaft", "ScienceBlogs", "Spiegel", "GEO", "Focus".

Keywords: heading, electronic popular science text, verbal component, non-verbal component.
«И нтернет-дискурс насыщен и перегружен информацией, и из-за этого большинство публикаций теряются для читателя» $[1,166]$, поэтому авторы текстов стремятся создать такой заголовок, чтобы читатель остановил на нем взгляд, заинтересовался прочтением. Заголовок - коммуникативно значимая составляющая структурной организации текста, прогнозирующая содержание и последующее восприятие содержания текста. Он является неотъемлемой частью электронного научно-популярного текста и «должен быть сформулирован таким образом, чтобы привлечь адресата-читателя, заинтересовать его и побудить прочитать...до конца» $[2,137]$. «...заголовки призваны привлечь внимание, сориентировать в тематической направленности текста и вызвать желание продолжить чтение» $[3,174]$, ведь это возможность сообщить о ценности исследования широкому кругу читателей-неспециалистов в данной области знания. Заголовок - первое, что видят читатели и что определяет их желание ознакомиться с предлагаемым текстом, значит, должен быть понятным и привлекательным. Он «играет роль своеобразного триггера в принятии читателем решения ознакомиться с материалом статьи» $[4,165]$. Заголовок текста «конструирует» его содержание: уже на этапе прочтения заголовка создается определенное представление о со-
Христофорова Наталья Игоревна

к.филол.н., доцент, Московский авиационный институт

n_khristoforova@mail.ru

Аннотация: Исследование заголовков электронного научно-популярного текста представляется актуальной темой, поскольку заголовки являются важной составляющей, «лицом» текста: они несут большую информационную нагрузку, представляя собой краткое описание содержания текста (краткую содержательно-смысловую информацию). Кроме того, заголовок является средством воздействия на читателя, ведь если читатель обратит внимание на заголовок и заинтересуется текстом, он переходит по ссылке непосредственно к публикации. В статье утоняется роль заголовка в процессе понимания электронного научно-популярного текста, анализируются вербальные и невербальные средства его создания. Учитывается и противоречивый характер заголовка: он может выступать как самостоятельная речевая единица и как равноправный элемент текста.

В статье представлены результаты анализа заголовков научно-популярных текстов из электронных вариантов немецкоязычных периодических изданий «Bild der Wissenschaft», «ScienceBlogs», «Spiegel», «GEO», «Focus».

Ключевые слова: заголовок, электронный научно-популярный текст, вербальная составляющая, невербальная составляющая.

держании и сюжете текста за счет создания ассоциативных связей в сознании потенциального читателя.

Заголовок научно-популярного текста является «максимально уникальным, при этом уникальность достигается не за счет употребления непривычных лексических единиц, а за счет комбинаторики распространенных лексико-грамматических конструкций» $[5,117]$ между собой и с невербальным материалом. От характера и оформления заголовка зависит воздействие текста на читателя: он может не обратить внимания на содержательный текст с неинтересным заголовком и заинтересоваться простым текстом с выразительным заголовком. Графическое оформление заголовка, его расположение, длина строки, пробелы, шрифт, цвет, курсив играют важную роль в реализации его аттрактивной функции. «Оформление заголовка определяет решение читателя прочитать следующий за ним текст или оставить его без внимания. [6, 132].

«Заголовок является одним из основных компонентов успешности публикации» $[7,104]$, а именно такова цель создания научно-популярного текста: ознакомить читателей-неспециалистов с новостями из мира науки и техники. В названии текста предельно кратко формули- 
руется основное достижение исследовательской работы, о которой рассказывается в популярной форме. Отметим, что в случае автора научно-популярного текста и его потенциального читателя автор ориентируется на читателя-«себя», ведь ему не остается ничего иного, поскольку единственный известный ему критерий, по которому можно судить о читателе - множественное число (читателей больше одного). Тем не менее, коммуникация между автором и читателем происходит на всех уровнях их языковых личностей: на вербально-семантическом, когнитивном и мотивационном, а заголовок является логической основой аргументированного убеждения адресата текста и обеспечивает взаимодействие автора и читателя.

Для электронных текстов в целом и для научно-популярных электронных текстов в частности характерно не только сочетание вербальной и невербальной составляющих, но и наличие целого ряда медийных особенностей, связанных с возможностями, предоставляемыми Интернетом (гиперссылки, видео- и аудиофайлы и т.д.). Особого внимания заслуживает построение заголовков научно-популярных электронных текстов, так как, в отличие от традиционных печатных научно-популярных текстов, читатель ориентируется только на заголовок, пока не откроет полный текст: «С развитием Интернета и всеобщего доступа к информации перед журналистами встала непростая задача - привлечь внимание читателей с помощью одного лишь заголовка» $[8,621]$, создать «концентрат» содержания текста и упростить его восприятие, установив контакт с читателем.

Так как в нашей работе исследуются заголовки немецкоязычных научно-популярных текстов, назовем их особенности: широкий круг тем, относящихся к миру науки, объективность при передаче информации, а также анонимность адресата (единственная известная его характеристика - многочисленность). Стоит выделить и варианты указания информации об авторе: в краткой или подробной форме (в том числе с фотографией). Возможна и анонимность автора - в этом случае статья публикуется без подписи, являясь выражением коллективного мнения редакции.

Анализ практического материала указывает на преобладание у научно-популярных текстов заголовков, относящихся к категории информирующих (в отличие от заголовков интригующих, направленных в первую очередь на привлечение внимания читателя к тексту). Это в некоторой степени дает возможность читателю не обращаться к полному тексту, а задействовать «просмотровое или «лоскутное» чтение» $[9,863]$. Такой тип чтения обусловлен постоянно растущим объемом поступающей информации, в том числе из мира науки и техники, а также недостатком времени у читателя для полного ознакомления со всеми материалами отдельного номе- ра издания. По этой причине читатель часто ограничивается прочтением заголовков, что ставит перед автором текста задачу помочь читателю сориентироваться в большом количестве текстов и способствовать тому, чтобы тот выбрал для подробного ознакомления конкретный текст, создав для этого выразительный, привлекательный заголовок. Так, например, прочитав следующие заголовки рубрики «Tiere» журнала «Spiegel»:

— Millionen Jahre alter »Adlerhai« entdeckt [10] (об apхеологическом открытии)

- Warum Gorillas bei der Balz auf ihre Brust trommeln [11] (об изучении поведенческой психологии животных)

- Flieger, grüß mir die Katze [12] (об исследовании невесомости с помощью кошек)

Читатель решит, стоит ли перейти по ссылке и прочитать какой-то из этих текстов, а, возможно, и не один из них. Следовательно, заголовок представляет собой «конструкт, служащий потенциальному реципиенту для получения первичной информации о тематике материала в отсутствие знакомства с ним» $[13,205]$. Отметим, что просмотровое чтение определяет основную задачу заголовка - максимально полное сообщение темы текста и одновременно с этим привлечение внимания читателя к нему. Заголовки становятся особенно важными в процессе передачи читателю информации о содержании статьи, что, в свою очередь, влияет на процесс создания заголовка и его концептуальную природу.

В процессе работы у автора формируется представление о том, каким должен быть заголовок этого научнопопулярного текста для его правильной интерпретации читателем, какие средства максимально точно и ясно отразят необходимое содержание. Подчеркнем, что заголовки научно-популярных текстов должны точно описывать содержание исследования, быть лаконичными и в тоже время информативными, использовать только общепринятые сокращения, не содержать «пустых» и общих слов. В приведенных далее примерах заголовки достаточно информативны, независимо от длины сформулировано основное достижение исследования, его результат или вывод. Такие заголовки в наукометрии называются «утвердительными» (declarative titles), их высокая информативность достигается в первую очередь благодаря тому, что они сформулированы в виде полного предложения (sentence title). [см. 14].

Именно использование сказуемого, выраженного глаголом (zeigen, helfen, entdecken, lösen, bestätigen и др.), придает названию конкретику и утвердительный характер:

Studie zeigt deutliche Ausdehnung der jährlichen Pollenflug-Saison;

Finnwale-Rufe helfen Seismologen bei MeeresbodenUntersuchung; 
Archäologen entdecken einen römischen Festwagen;

Forscher lösen legendäres Matherätsel um die Zahl 42;

Echtheit und Alter bestätigt: Forscher lüften Geheimnisse um „Hand aus Metall“

«Утвердительные» заголовки научно-популярного текста, несомненно, привлекают внимание читателей, если научные выводы, описываемые в тексте, основаны на достоверных сведениях и фактическом материале, полученных от исследователей или из их научных статей, например:

- Astronomen entdecken 426 Grad heiße Super-Erde;

- 10.000 Jahre altes Mammut-Skelett mit Gewebe und Haaren ausgegraben;

Высокоинформативными являются заголовки, фокусирующие внимание на узких аспектах исследования виде/роде растений или животных, живущих ныне или ископаемых, влиянии на здоровье человека различных факторов, в том числе климатических, событиях/находках (в том числе археологических) в конкретной стране или географическом регионе, на конкретной проблеме, например:

- Lunge hilft Laubfröschen beim Hören;

- Corona-Masken schützen vor Pollen und können so Symptome lindern;

- Verändert Hirnzellen: Was Handystrahlung mit Ihnen macht - und wie Sie sich schützen;

- Klimaanlagen gegen die Erderwärmung;

- Schweden baut Dutzende neue Brücken - für Rentiere;

- Dutzende Amphoren aus der Antike vor Kasos entdeckt;

- Marianengraben. Vorbild Fisch: Neuer Roboter kann tiefste Stelle des Ozeans erforschen;

- Wege aus der Antibiotika-Krise;

- Warum wir intuitiv gegen Gentechnik sind

Как видно из приведенных примеров, такие показатели, как географическая привязка Kasos, Schweden, Marianengraben; вид животных Oktopusse, Rentiere, Laubfrösche; факторы, влияющие на здоровье человека Corona-Masken schützen, Verändert Hirnzellen, название проблемы Antibiotika-Krise, Gentechnik, Erderwärmung повышают информативность заголовка и способствуют появление интереса у читателя.

В отличие от «утвердительных» (declarative) [см. 14], «описательные» заголовки (descriptive titles) [см. 14] называют объект повествования, но не содержат основных результатов и выводов из него:

- Heißer Kandidat für die Atmosphären-Forschung;

- Die Gefahren der Fett-weg-Spritze;

- Wo die Finken Blut trinken;

- Sternengeschichten Folge 431: Begegnungen zwischen der Sonne und anderen Sternen.
Отметим, что современные возможности поиска информации снизили важность информативных заголовков. Нужную информацию можно найти с помощью поисковых систем, которые постоянно совершенствуются и дают возможность поиска не только по названию, но и по ключевым словам, фрагментам текста и аннотациям.

Распространенной формой заголовка научно-популярного текста является так называемый двухчастный заголовок (compound title) [см. 14]. В его первой части содержится главная мысль, во второй - уточнение (второстепенная информация) которое приводится после двоеточия. Второстепенная информация объясняет или расширяет основную идею. Двухчастная структура заголовка с двоеточием очень удобна для четкого и компактного оформления названий. Преимущество таких заголовков в том, что они содержат сведения как общего, так и более узкого характера и поэтому являются в высшей степени информативными. Например:

Graffiti-Verschlüsselung gelöst: Hat sich der Urheber selbst verraten? [15]

Автор текста:

1. Сообщает информацию - «зашифрованная надпись расшифрована»

2. Явно указывает, что автор надписи указал на себя, а, значит, «помог», вольно или невольно, с расшифровкой.

Neandertaler: Hinweis auf Sprachfähigkeiten [16]

Автор текста:

1. Сообщает информацию - получены новые сведения о неандертальцах

2. Максимально кратко передает суть новых данных: «обнаружены указания на наличие речи».

Значительно реже научно-популярных текстах встречаются заголовки с использованием тире, вопросительного знака или их сочетания:

Ein Drittel aller Süßwasserfische in Gefahr - die Gründe sind vielfältig [17], Der Stärkste überlebt? Von wegen! Die größten Missverständnisse der Evolution [18],

Glücksforschung - Was wissen wir über das Glück? [19].

Судя по приведенным примерам, вторая часть заголовка явно указывает, как текст объяснит проблему или ответит на поставленный вопрос. Такая формулировка заголовка, с одной стороны, привлекает внимание читателя, вызывает его интерес, с другой стороны - дает конкретный ответ, делая заголовок информативным.

Тире выполняет в научно-популярном тексте функ- 
цию логического ударения, служит выразительным средством, средством выражения эмоций. Так, название текста, посвященного изучению улиток, можно перевести следующим образом: «Улитка обезглавливает себя и ползет дальше» - Schnecke köpft sich selbst - und kriecht weiter [20]

Автор призывает читателя удивиться («Как же так? Не может быть!») и способствует появлению интереса к тексту.

Актуализации образности в заголовке способствуют кавычки. Обычно кавычками выделяются слова, употребляемые иронически (таких случаев в научно-популярных текстах нами выявлено не было) или в переносном значении. Так, например, в заголовке текста о платежных средствах Бронзового века "Schrott“ mit Kaufkraft [21] автор употребляет слово, которое можно перевести как «лом, хлам, металлолом» - кавычки сигнализируют о различии понятий человека Бронзового века и современного человека: то, что тогда считалось «деньгами» для нас просто «мусор».

«В восприятии косвенной оценочности основу составляет декодирование и вычленение дополнительных, подразумеваемых, дескрипционных смыслов высказывания, т. е. понимание эмоциональной, оценочной, функционально-стилистической информации» $[22,139]$. Таким образом, заголовок - посредник в интерпретации текста и читателем, его эмоционально-ценностной сферой, опытом, объемом фоновых знаний читателя. Вследствие этого сознании читателя формируется визуальный образ, например, образ "тормозного» пути - следа из пластика, который оставляют за собой суда, загрязняя этим окружающую среду: Schiffe hinterlassen „Bremsspur“ aus Mikroplastik [23]

Заголовок воспринимается читателем на основании предшествующих знании - новая информация соотносится с уже выстроенной понятийной системой читателя. Поскольку заголовок направлен на то, чтобы заинтересовать и привлечь внимание читателя, его задача - изменить с помощью новой информации эмоциональное состояние читателя, и внедрить оценку содержания научно популярного текста в форме:

- утверждения, рассуждения, объяснения поступков, признание ошибок:

Toast mit grünem Nutri-Score? Warum die Nährstoffampel ihren Zweck verfehlt [24] (Тост с зеленым показателем? Почему «Пищевой светофор» не действует)

- сожаления, самоанализа, рефлексии: Die Simulationshypothese: Leben wir in einem Computerprogramm? [25] («Гипотеза симуляции: мы живём в компьютерной программе?»);

- самопрезентации: Archäologe über Grabungen:
«Mein Tag beginnt lange vor ersten Sonnenstrahlen» [26] (Археолог о раскопках: «Мой день начинается задолго до первых лучей солнца») ;

- упрека, намека, желания удивить Ich brauche Ruhe! Drei Bücher, die zeigen, dass Einfachheit glücklich macht [27] («Мне нужен покой! Три книги, которые показывают, что простота приносит счастье»);

- разъяснения, утверждения своей точки зрения, сложившейся ситуации: Stadtgärten sind „Schlaraffenland“ für Insekten [28] («Городские сады - рай для насекомых»);

- поучения: «Stress ist der Preis, den wir für unsere Gesellschaftsform zahlen» [29] («Стресс - та цена, которую мы платим за нашу форму общества»);

Условиями успешности использования оценки в позиции заголовка научно-популярного текста можно считать лингвистические ситуации, когда автор владеет информацией, которая может быть, по его мнению, интересна читателю-неспециалисту в рассматриваемой области, когда адресант старается убедить читателя в своей точке зрения, а также когда автор учитывает необходимость экономии языковых средств в заголовке и краткой формулировки темы текста. Оценочный компонент в заголовках научно-популярных текстов служит приемом актуализации темы текста, приемом формулировки тезисов, а также выделения основной идеи передаваемой информации.

В заголовке научно-популярного текста важна аттрактивная составляющая, поскольку удачные заголовки, привлекая внимание читателя, способствуют повышению рейтинга как текста, так и издания в целом. В рассмотренном материале при оформлении заголовка используются различные виды шрифта, кегль и цветовая палитра:

- На сайте «ScienceBlogs» заголовки текстов больше по размеру, чем основной текст и выполнены жирным черным шрифтом;

— В разделе «natur.de» («Природа») издания «Bild der Wissenschaft», посвященной природе и окружающей заголовки текстов заголовки текстов больше по размеру, чем основной текст и выполнены зеленым цветом, в разделе «Nachrichen+Themen» того же издания (как и в большинстве разделов) («Новости +темы») цвет заголовков синий, заголовки текстов заголовки текстов больше по размеру, чем основной текст, а в разделе «damals. de», посвященном истории и археологии, цвет заголовков красный, заголовки текстов заголовки текстов больше по размеру, чем основной текст;

- На сайте «GEO» заголовки всех текстов значительно крупнее (в 2 или 3 раза) и выполнены жирным черным шрифтом;

- На сайте «Focus» заголовки выполнены жирным черным шрифтом и крупнее основного текста;

- На сайте «Spiegel», заголовки выполнены жирным 
черным шрифтом и крупнее (в 2 раза) основного текста.

На основании проведенного исследования заголовков научно-популярных текстов можно выделить их следующие особенности:

- лаконичность и вместе с тем информативность;

- отражает суть описываемого исследования (открытия), не вдаваясь в детали;

- отсутствие так называемых «пустых» слов типа: исследование, изучение;

- привлечение интереса читателя с помощью двухчастных структур, формулировок в виде вопроса;
- шрифтовое оформление, отличное от остального текста.

Для реализации своих функций - информативной, текстообразующей, компрессионной, контактоустанавливающей, аттрактивной и оценочной - заголовок научно-популярного текста должен быть содержательным, ярким и выразительным. Для выполнения этой задачи задействуются лексические, грамматические и стилистические средства выразительности, а также невербальные средства. При этом функции заголовка гармонично существуют в комплексе, и не всегда можно выделить среди них доминирующую.

\section{ЛИТЕРАТУРА}

1. Торопкина В.А. Функции новообразований в заголовках электронных средств массовой информации // «Научный диалог», Екатеринбург, 2019. № 5, с.154-168.

2. Красина Е.А., Садукия Мунья Англоязычные газетные заголовки онлайн как явление медиалингвистики (опыт лингвистического описания)//Вопросы теории и практики журналистики, Иркутск, 2020. Том 9, № 1, с.136-148

3. Цвенгер Л.В. Колоративные коллокации и их функции в газетном заголовке//Вестник ЧГу, Челябинск, 2020. № 1 (435), с.173-180.

4. Нухов С.Ж. Игра шрифтом как модный графический прием языковой игры в медийных заголовках//Вестник Башкирского университета, Уфа, 2018. Том 23, № 1, с.164-172

5. Никонова Е.В. Лингвопрагматические особенности названий современных компьютерных игр жанров «HIDDEN OBJECT/ADVENTURE»//Bectник MГЛУ. Гуманитарные науки, Москва, 2020. № 6 (835), с.108-118.

6. Никитина М.А. Роль метафоры в реализации компрессивной и аттрактивной функций заголовков экономических статей на немецком языке//Известия Волгоградского государственного педагогического университета, Волгоград, 2017. № 7 (120), с.130-133.

7. Захарова Т.В., Снигирева 0.М. Языковая специфика немецкоязычных газетных заголовков и практические трудности при их переводе на русский язык// Вестник Оренбургского государственного университета, Оренбург, 2017. № 7 (202), с.102-105.

8. Аргунов Т.В., Пермякова Т.Н., Лексикосинтаксические средства языкового манипулирования в японских газетных заголовках о COVID-19 (на материале интернет-сайта Hokkaido Shimbun)// Мир науки, культуры, образования, Горно-Алтайск, 2020. № 6 (85), с.621-623.

9. Чертоусова С.В. Структура и свойства концепта экономический заголовок в немецкоязычной лингвокультуре//Вестник Кемеровского государственного университета, Кемерово, 2019. Том 21, № 3 (79), с.860-868

10. koe/dpa. Millionen Jahre alter »Adlerhai« entdeckt// Spiegel. 2021. [электронный ресурс] - Режим доступа. - URL: https:/www.spiegel.de/wissenschaft/ natur/mexiko-millionen-jahre-alter-adlerhai-aus-der-kreidezeit-entdeckt-a-c515990e-911f-42e4-acf9-b04d8e476с64 (дата обращения: 18.03.2021)

11. sug/dpa. Warum Gorillas bei der Balz auf ihre Brust trommeln// Spiegel. 2021. [электронный ресурс] - Режим доступа. - URL: https://www.spiegel.de/ wissenschaft/natur/verhaltensforschung-warum-gorillas-bei-der-balz-auf-ihre-brust-trommeln-a-4b5319bb-5774-4964-965b-09abb74bbb69 (дата 0бращения: 09.04.2021)

12. Grothe, Solveig. Flieger, grüß mir die Katze// Spiegel. 2021. [электронный ресурс] - Режим доступа. - URL: https://www.spiegel.de/geschichte/ein-bild-undseine-geschichte-die-katze-im-kampfjet-a-582e5cbe-1045-42b2-9afc-5a9d51d6c10е (дата обращения: 11.04.2021)

13. Чертоусова С.В. Концептуальная природа заглавия немецкоязычного газетного текста//Филологические науки. Вопросы теории и практики, Тамбов, 2020. Том 13, № 8, c.203-208

14. Комарова А.И., Окс И.Ю. Что значит effective, informative, attractive, search-engine-friendly titles? Анализ названий научных статей по географии на английском языке//Вестник МГУ. Серия 19: Лингвистика и межкультурная коммуникация, Москва, 2018. № 2, с.9-22

15. Schmeh, Klaus. Graffiti-Verschlüsselung gelöst: Hat sich der Urheber selbst verraten?//ScienceBlogs. 2021. [электронный ресурс] - Режим доступа. URL: https://scienceblogs.de/klausis-krypto-kolumne/2021/03/10/graffiti-verschluesselung-geloest-hat-sich-der-urheber-selbst-verraten/ (дата обращения: 10.03.2021)

16. Vieweg, Martin. Neandertaler: Hinweis auf Sprachfähigkeiten//Bild der Wissenschaft. 2021. [Электронный ресурс] — Режим доступа. — https://www.wissenschaft.de/geschichte-archaeologie/neandertaler-hinweis-auf-sprachfaehigkeiten/(дата обращения: 01.03.2021)

17. Cartens, Peter. Ein Drittel aller Süßwasserfische in Gefahr - die Gründe sind vielfältig// GE0. 2021. [электронный ресурс] - Режим доступа. URL: https://www.geo.de/natur/oekologie/24060-rtkl-wwf-report-ein-drittel-aller-suesswasserfische-gefahr-die-gruende-sind (дата 0бращения: 20.05.2021)

18. Sackmann, Christoph. Der Stärkste überlebt? Von wegen! Die größten Missverständnisse der Evolution// Focus 2021. [электронный ресурс] - Режим доступа. - URL: https://www.focus.de/wissen/natur/evolution/es-gibt-keinen-survival-of-the-fittest-wir-stammen-nicht-vom-affen-ab-was-sie-an-evolutionimmer-falsch-verstanden-haben_id_6682797.html (дата обращения: 24.04.2021)

19. Teske, Elias. Glücksforschung - Was wissen wir über das Glück?//ScienceBlogs. 2021. [электронный ресурс] - Режим доступа. - URL: https://scienceblogs.de/ 
wissens-ecke/2021/02/19/gluecksforschung-was-wissen-wir-ueber-das-glueck/ (дата обращения: 19.02.2021)

20. koe/dpa. Schnecke köpft sich selbst - und kriecht weiter// Spiegel. 2021. [электронный ресурс] - Режим доступа. - URL: https://www.spiegel.de/wissenschaft/ mensch/das-patriarchat-ist-eine-anomalie-in-der-menschheitsgeschichte-a-00000000-0002-0001-0000-000174103658 (дата 0бращения: 09.03.2021)

21. Vieweg, Martin. „Schrott“ mit Kaufkraft//Bild der Wissenschaft. 2021. [Электронный ресурс] — Режим доступа. — https://www.wissenschaft.de/geschichtearchaeologie/schrott-mit-kaufkraft/ (дата обращения: 11.05.2021)

22. Смирнова Н.В., Советов И.М. Авторская самооценка в заголовках современных печатных СМИ// Известия Волгоградского государственного педагогического университета, Волгоград, 2019. № 6 (139), с. 135-140.

23. Bolten, Anna. Schiffe hinterlassen „Bremsspur“ aus Mikroplastik//Bild der Wissenschaft. 2021. [Электронный ресурс] — Режим доступа. — https://www.wissenschaft.de/umwelt-natur/schiffe-hinterlassen-bremsspur-aus-mikroplastik/ (дата обращения: 26.02.2021)

24. Niemeier, Heike. Toast mit grünem Nutri-Score? Warum die Nährstoffampel ihren Zweck verfehlt// GE0. 2021. [электронный ресурс] - Режим доступа. URL: https://www.geo.de/natur/oekologie/23308-rtkl-waldbraende-den-usa-warum-sieht-der-himmel-ueber-kalifornien-so (дата обращения: 19.05.2021)

25. Freistetter, Florian. Die Simulationshypothese: Leben wir in einem Computerprogramm?//ScienceBlogs. 2021. [электронный ресурс] - Режим доступа. https://scienceblogs.de/astrodicticum-simplex/2021/02/22/die-simulationshypothese-leben-wir-in-einem-computerprogramm/(дата 0бращения: 22.02.2021)

26. Tepe, Göbekli. Archäologe über Grabungen: «Mein Tag beginnt lange vor ersten Sonnenstrahlen»// Focus 2020. [электронный ресурс] - Режим доступа. URL: https://www.focus.de/wissen/mensch/archaeologie/mehr-als-nur-buddeln-arbeit-beginnt-lang-vor-sonnenaufgang-zu-besuch-bei-den-ausgraebern-vongoebekli-tepe_id_12653117.html (дата обращения: 13.11.2020)

27. Brigger, Patrick. Ich brauche Ruhe! Drei Bücher, die zeigen, dass Einfachheit glücklich macht// Focus 2018. [электронный ресурс] - Режим доступа. URL: https://www.focus.de/wissen/mensch/einfach-besser/minimalismus-und-paretoprinzip-ich-brauche-ruhe-drei-buecher-zum-tag-der-einfachkeit_ id_9241544.html (дата обращения: 13.05.2021)

28. Bolten, Anna. Stadtgärten sind „SChlaraffenland“ für Insekten //Bild der Wissenschaft. 2021. [Электронный ресурс] — Режим доступа. — https://www.wissenschaft.de/umwelt-natur/stadtgaerten-sind-schlaraffenland-fuer-bestaeuberinsekten/ (дата обращения: 24.02.2021)

29. GEO Wissen. «Stress ist der Preis, den wir für unsere Gesellschaftsform zahlen»// GE0. 2021. [электронный ресурс] - Режим доступа. URL: https://www.geo.de/wissen/gesundheit/24019-rtkl-interview-stress-ist-der-preis-den-wir-fuer-unsere-gesellschaftsform (дата 0бращения: 17.05.2021)

(с) Христофорова Наталья Игоревна (n_khristoforova@mail.ru).

Журнал «Современная наука: актуальные проблемы теории и практики»

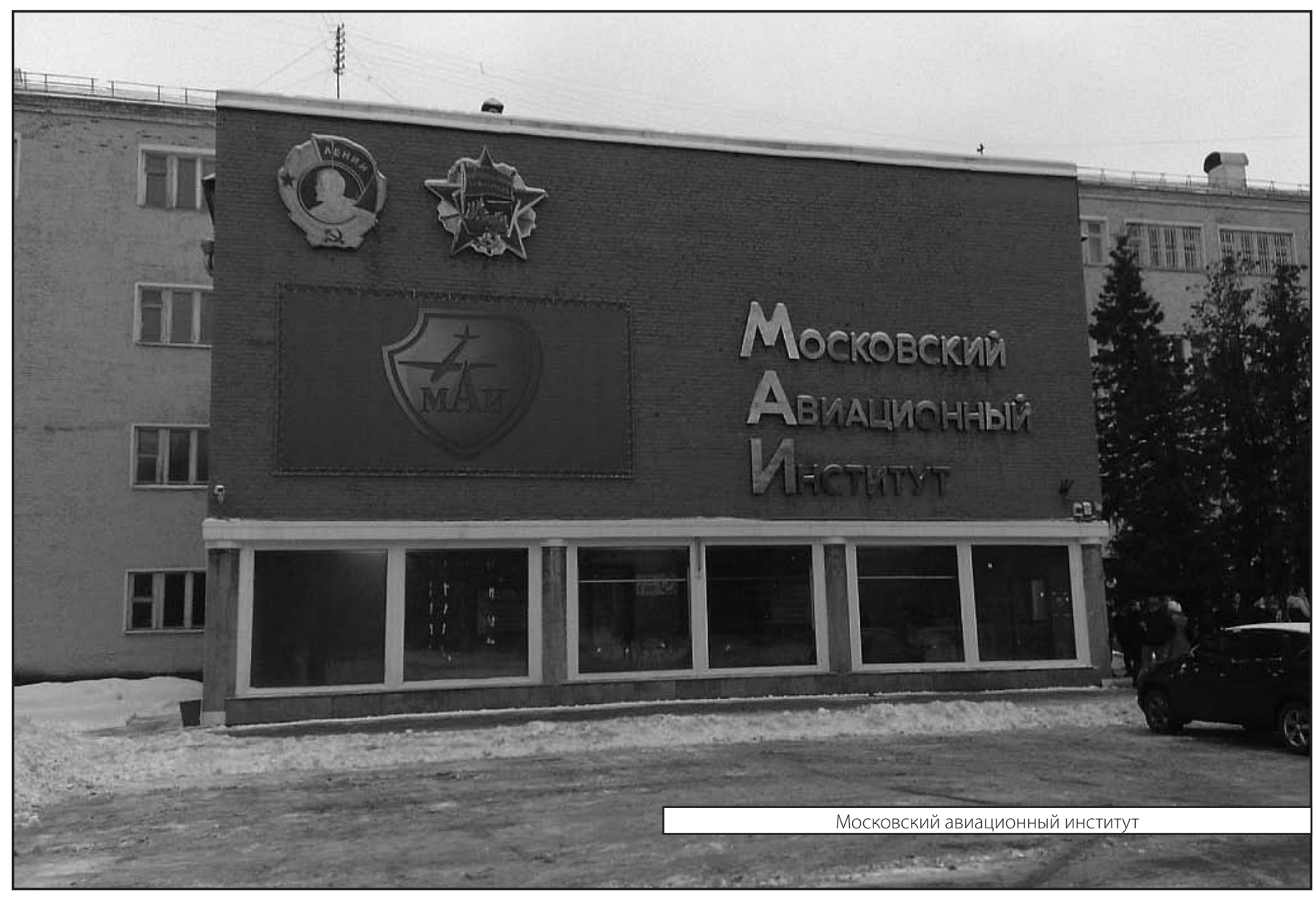

